\title{
The Impact of the Progressive Efficiency Test on a Rowing Ergometer on White Blood Cells Distribution and Clinical Chemistry Changes in Paralympic Rowers During the Preparatory Stage Before the Paralympic Games in Rio, 2016 - A Case Report
}

\author{
by \\ Robert Nowak ${ }^{1,2}$, Rafał Buryta1,2, Krzysztof Krupecki ${ }^{1}$, Tomasz Zając ${ }^{3}$, \\ Marek Zawartka ${ }^{4}$ Patrizia Proia ${ }^{5}$, Dorota Kostrzewa-Nowak ${ }^{1,2}$
}

There is a large gap in knowledge regarding research on post-exercise blood changes in disabled athletes. There are relatively few data on adaptive mechanisms to exercise in disabled athletes, including disabled rowers. Two rowers from a Polish adaptive rowing settle TAMix $2 x$ that qualified for the Paralympic Games in Rio, 2016 took part in this study. They performed a progressive test on a rowing ergometer until exhaustion. The cardiorespiratory fitness measures, complete blood count, white blood cells' distribution and 30 clinical chemistry variables describing laboratory diagnostic profiles and general health were determined. The extreme effort induced changes in all studied metabolites (glucose, creatinine, urea, uric acid, total and direct bilirubin), albumin, total protein levels in both participants. Furthermore, a post-exercise increase in aspartate transaminase activity, yet a 2-fold decrease during the recovery time in both rowers were found. White blood cell count increased 2-fold after the test. The percentages of natural killer cells were higher and total $T$ lymphocytes were lower after the exercise protocol. There were higher percentages of suppressor/cytotoxic and lower percentages of helper/inducer $T$ lymphocyte subsets in both studied rowers. No changes in B lymphocytes distribution were observed. Lack of inflammatory symptoms during the experiment suggests a high level of rowers' biological adaptation to the physical effort. The different changes in physiological, biochemical and immunological variables are related to the adaptive mechanism to physical exercise allowing for improvement of performance.

Key words: adaptive rowing, biochemical markers, disabled athletes, Paralympic Games.

\section{Introduction}

Long-term and intensive physical effort causes metabolic and biochemical adaptation for both athletic and non-athletic populations. It influences the athletes' cellular metabolism and can lead to muscle damage, as well as induce oxidative stress that causes metabolic changes at a biochemical level reflected in diagnostic variables of athletes' blood (Banfi et al., 2012; Fallon, 2008).

\footnotetext{
1 - Faculty of Physical Education and Health Promotion, University of Szczecin, Szczecin, Poland.

2 - Centre for Human Structural and Functional Research, Faculty of Physical Education and Health Promotion, University of Szczecin, Szczecin, Poland.

3 - Human Performance Laboratory, The Jerzy Kukuczka Academy of Physical Education in Katowice, Poland

4 - Department of Theory and Practice of Sport, The Jerzy Kukuczka Academy of Physical Education in Katowice, Poland

5 - Department of Psychological, Pedagogical and Educational Sciences, Sport and Exercise Sciences Research Unit, University of Palermo, Palermo, Italy
} 
Each training cycle of rowers is aimed at increasing individual's physical fitness level. Coaches want to make the training process as efficient as possible. It is well known that adequate training performed during the season causes a disturbance of homeostasis among athletes. There are well described metabolic variables belonging to sports markers used by coaches and athletes to follow and characterise their strength and efficiency, such as creatine kinase activity, and blood lactate concentration (Banfi et al., 2012; Chamera et al., 2014, 2015). Training and competition provoke exercise-induced muscle damage resulting in the release of inflammatory signalling molecules and myocellular enzymes into the athletes' blood. There is a thin line between the desired stimulation and overreaching or overtraining, especially during the preparatory stage before prestigious competitions like the Olympic Games.

It should be emphasized that there is a large gap in research regarding post-exercise blood changes in disabled athletes. There is little data on the adaptive mechanisms to exercise in disabled athletes. This is probably due to difficulties in gathering a homogenous group of athletes. Rowing, representing an endurance sport discipline, is characterized by very intense competition efforts. Adaptive rowing is a category for athletes with physical disabilities. There is vast literature data concerning wide aspects of rower athletes' analysis (Akça, 2014; Buckeridge et al., 2015; Gee et al., 2016; Kyparos et al., 2012; Shaharudin and Agrawal, 2016; SkarpańskaStejnborn et al., 2015; Tran et al., 2015). However, to the best of our knowledge, there are only few studies describing disabled rowers (Schaffert and Mattes, 2015; Smoljanovic et al., 2011, 2013).

Therefore, the aim of this study was to evaluate changes in biochemical and haematological variables of two highly skilled rowers during the preparatory stage to the Paralympic Games in Rio, 2016.

\section{Methods}

\section{Study design}

To better understand biological response to exhaustive exercise in elite disabled athletes, we designed an experiment to evaluate these processes. We determined cardiorespiratory fitness measures (maximum oxygen uptake $\left(\mathrm{VO}_{2 \max }\right)$, maximum heart rate $\left(\mathrm{HR}_{\max }\right)$, maximum ventilation $\left(\mathrm{V}_{\mathrm{E}}\right)$, anaerobic threshold $(\mathrm{AT})$ ), complete blood count, white blood cells distribution and 30 clinical chemistry variables relevant to the well-known laboratory diagnostic profile e.g. liver, muscles, kidney and general health of the athletes. The study was performed during the preparatory stage of the Paralympic Games in Rio, 2016, in the biochemistry and physiology laboratories of the Centre for Human Structural and Functional Research, Szczecin, Poland.

\section{Participants}

Two rowers aged 26 and 38 years for the male and female participant, respectively, met inclusion criteria for the study. It was a Polish adaptive rowing settle TAMix $2 x$ that qualified for the Paralympic Games in Rio, 2016. TAMix 2x (mixed double sculls) is an adaptive rowing settle qualified as a double scull, with the man and woman using only upper body muscles. It is a category of rowing for athletes with physical disabilities. Their body height was equal to 178 and $168 \mathrm{~cm}$, body mass, 65.9 and $64.0 \mathrm{~kg}$, body mass index, 20.8 and $22.7 \mathrm{~kg} / \mathrm{m}^{2}$, respectively, for the male and female participant. The male rower declared 6 years while the female rower 10 years of training experience. Both participants trained 9 hours a week. The participants were non-smokers and refrained from taking any medications or supplements known to affect the metabolism. They had no history of any metabolic syndrome (as defined by International Diabetes Federation: diabetes, prediabetes, abdominal obesity, high cholesterol and high blood pressure) (The IDF Consensus, 2014) or cardiovascular diseases (defined by WHO as disorders of the heart and blood vessels) (WHO, 2014).

The rowers were informed of the experimental procedures and the possible risks and benefits of the study before providing their written consent to participate. The study was approved by the Local Ethics Committee and in accordance with the Helsinki Declaration.

\section{Procedures}

Aerobic capacity evaluation

The progressive exercise protocol was preceded by $5 \mathrm{~min}$ of free rowing as a warm-up. The formal test began with continuous rowing at $40 \mathrm{~W}$ output power on a Concept2 model D 
rowing ergometer (Concept2, Morrisville, VT, USA) for $3 \mathrm{~min}$. After this phase, the workload was systematically increased by $40 \mathrm{~W}$ every $3 \mathrm{~min}$ until exhaustion. The effort was interrupted when rowing frequency declined by $10 \%$. The heart rate registered at this point was noted as HRmax. The cardiorespiratory fitness measures obtained during the progressive test were determined using a breath by breath gas exchange data analyser Quark CPET (Cosmed, Italy). Moreover, every 3 minutes of the exercise, before increasing the workload, capillary blood samples were taken for determination of lactate (LA) concentration and determining the anaerobic threshold (AT) (Beaver et al., 1986). The LA concentrations were determined using a mobile blood lactate monitoring system (THE EDGE Lactate Analyser, Apex Biotechnology Copr., Hsinchu, Taiwan).

Blood sampling

Blood samples were obtained three times from the elbow vein. The first drawing of fasting blood took place in the morning the day before testing. The second blood sample was taken no longer than $5 \mathrm{~min}$ after the exercise test. It should be noted that, for safety reasons, the test protocol required the participant to be after a light breakfast. Therefore, blood samples collected after the test were not fasting blood. About 17 hours after the test, at the end of the recovery period, the third blood sample was drawn in the morning before breakfast.

Each time, blood samples from the rowers were drawn into two tubes. For biochemical analyses, a $7.5 \mathrm{~mL}$ S-Monovette tube for serum preparation with an additive carrier of a colt activator (SARSTEDT AG \& Co., Nümbrecht, Germany) was used. For complete blood count and blood phenotyping, a $7.5 \mathrm{~mL}$ S-Monovette tube with ethylenediaminetetraacetic acid (EDTA $\mathrm{K}_{3}, 1.6 \mathrm{mg}$ EDTA/mL blood) (SARSTEDT AG \& Co., Nümbrecht, Germany) was used. Blood samples for biochemical analyses were centrifuged $2000 \times \mathrm{g}$ for $10 \mathrm{~min}$ at room temperature in order to obtain blood serum or plasma, respectively.

Biochemical and haematological analyses were performed before the progressive test (preexercise), after the test (post-exercise) and at the end of recovery (17 hours after completion of the test). The analyses were performed immediately after blood collection.
Complete blood count

Complete blood count, including white blood cells (WBC), red blood cells (RBC), haemoglobin (HGB), haematocrit (HCT), mean corpuscular volume $(\mathrm{MCV})$, mean corpuscular haemoglobin $(\mathrm{MCH})$, mean corpuscular haemoglobin concentration (MCHC), and total platelets level (PLT) was obtained with a haematology analyser ABX Micros 60 (Horiba ABX, Warsaw, Poland).

White blood cells phenotyping

Blood phenotyping was performed using the BD Multitest ${ }^{\mathrm{TM}}$ IMK kit (BD Biosciences, San Jose, CA, USA) and BD Accuri ${ }^{\mathrm{TM}} \mathrm{C6}$ flow cytometer (Becton Dickinson, Franklin Lakes, NJ, USA). The expression of surface markers was determined according to the manufacturer's protocol using two antibody cocktails to determine the percentages of $\mathrm{T}$ lymphocyte subsets (Th and Tc lymphocytes, respectively) as well as lymphocyte B and NK cells in erythrocytelysed blood samples. The samples were analysed by flow cytometry (BD Accuri C6, Becton Dickinson). For each sample, the fluorescence signal of $10^{4}$ events was measured and the results were calculated using $\mathrm{BD}$ Accuri $^{\mathrm{TM}} \mathrm{C} 6$ (ver. 1.0.264.21) software.

Biochemical analyses

Biochemical analyses were conducted using an Auto Chemistry Analyser BM-100 (BioMaxima S.A., Lublin, Poland) in case of clinical chemistry variables or an Ion Selective Analyser BM ISE (BioMaxima S.A., Lublin, Poland). Blood serum was used to determine metabolites (glucose, creatinine, urea, uric acid and bilirubin, both total and direct), albumin, total protein, ferritin, Creactive protein (CRP), lipid profile (triglyceride (TG), total cholesterol (TC), high-density lipoprotein cholesterol (HDL-C), low-density lipoprotein (LDL-C) levels), enzymes activities (aminotransferases: aspartate (AST) and alanine (ALT), gamma-glutamyltransferase (GGT), alkaline phosphatase (ALP), creatine kinase (CK), creatine kinase $\mathrm{MB}$ (CK-MB), lactate dehydrogenase (LDH), alfa-hydroxybutyrate dehydrogenase (HBDH), lipase and amylase) and selected ions, namely iron, magnesium, phosphorus (Auto Chemistry Analyser BM-100, BioMaxima, Poland), sodium, potassium, chloride and calcium (Ion Selective Analyser BM ISE, BioMaxima, Poland). All studied variables were determined using a diagnostic method according 
to the appropriate manufacturer's protocol (BioMaxima S.A., Lublin, Poland for most of them; Quimica Clinica Aplicada S.A., Amposta, Spain for ferritin; PZ Cormay S.A., Łomianki, Poland for $\mathrm{HBDH}$ and lipase). Moreover, the CRP level was determined using two different turbidimetric assay kits according to the manufacturers' protocols (BioMaxima S.A., Lublin, Poland and Quimica Clinica Aplicada S.A., Amposta, Spain) to confirm the results obtained during the study. All analyses were verified with the use of multiparameteric control serum, as well as control serum of a normal level (BioNorm) and a high level (BioPath) (BioMaxima S.A., Lublin, Poland).

To quantitatively measure the plasma level of inflammatory cytokines (interleukin-8 (IL8), interleukin-1 $\beta$ (IL-1 $\beta$ ), interleukin-6 (IL-6), interleukin-10 (IL-10), tumour necrosis factor (TNF), and interleukin-12p70 (IL-12p70)), the BD $^{\mathrm{TM}}$ CBA Human Inflammatory Cytokines Kit (BD Biosciences, San Jose, CA, USA) was used according to the manufacturer's protocol and analysed by flow cytometry (BD Accuri ${ }^{\mathrm{TM}}$ C6, Becton Dickinson). The flow cytometric data were calculated using FCAP Array ${ }^{\mathrm{TM}}$ Software (ver. 3.0.1; Soft Flow Hungary Ltd., Pecs, Hungary).

\section{Results}

Cardiorespiratory results achieved by the rowers during the test are presented in Table 1.
The intense effort performed during the study caused significant changes in all studied metabolites (glucose, creatinine, urea, uric acid, bilirubin), albumin, and total protein. The greatest changes were found in total and direct bilirubin levels in both participants (Table 2). No changes in GGT, ALT, CK, amylase activities in woman's serum, ALT, LDH, GGT, ALP activity in man's serum were observed, while increases in AST activity after the test yet a 2-fold decrease (compared to baseline values) during the recovery period in both rowers were found. No changes in the lipid profile of the participants (Table 2) as well as GGT, ALT, CK, amylase activities in the female athlete's serum and ALT, LDH, GGT, ALP activity in the male's serum were observed (Table 2).

Interestingly, it was found that the progressive rowing exercise test performed until exhaustion caused a 2.5-fold decrease in the iron level (from $30.6 \mu \mathrm{mol} / \mathrm{L}$ pre-exercise to 12.1 $\mu \mathrm{mol} / \mathrm{L}$ post-exercise and from $19.3 \mu \mathrm{mol} / \mathrm{L}$ preexercise to $7.4 \mu \mathrm{mol} / \mathrm{L}$ post-exercise for male and female rower, respectively), yet no changes in the ferritin level in both participants' post-exercise blood samples. Moreover, no changes in magnesium, sodium, potassium, chloride and calcium blood levels in both studied athletes were found.

\begin{tabular}{|c|c|c|}
\hline \multicolumn{3}{|c|}{$\begin{array}{l}\text { The cardiorespiratory fitness measures obtained during } \\
\text { the progressive exercise test on a rowing ergometer until exhaustion }\end{array}$} \\
\hline & Male participant & Female participant \\
\hline $\mathrm{VO}_{2 \max }[\mathrm{mL} / \mathrm{kg} / \mathrm{min}]$ & 58.4 & 52.4 \\
\hline $\mathrm{HR}_{\max }[$ beats/min] & 200 & 186 \\
\hline AT [beats/min] & 143 & 132 \\
\hline $\mathrm{RQ}$ & 1.31 & 1.18 \\
\hline $\mathrm{RC}$ & 168 & 151 \\
\hline $\mathrm{VE}_{\mathrm{E}}[\mathrm{L} / \mathrm{min}]$ & 104 & 111 \\
\hline $\operatorname{MVV}[\mathrm{L} / \mathrm{min}]$ & 186 & 167 \\
\hline MET $[\mathrm{mL} / \mathrm{kg} / \mathrm{min}]$ & 16.7 & 14.0 \\
\hline $\mathrm{Rf}$ & 37.1 & 33.2 \\
\hline \multicolumn{3}{|c|}{ 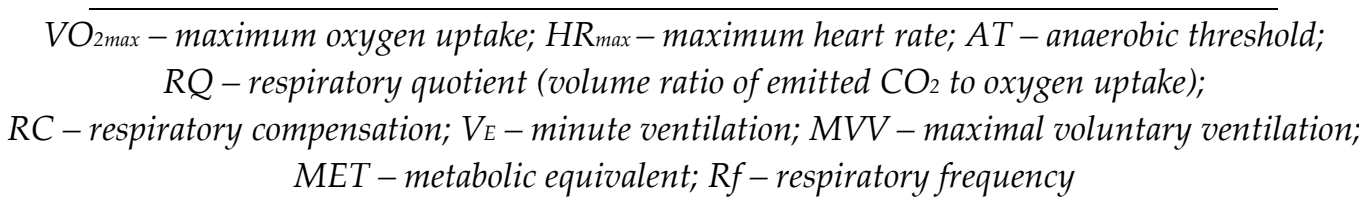 } \\
\hline
\end{tabular}


Table 2

Serum selected metabolite levels, lipid profile and enzyme activities of both participants determined before (pre-exercise) and after the progressive exercise test on a rowing ergometer until exhaustion (5 minutes post-exercise

\begin{tabular}{|c|c|c|c|c|c|c|}
\hline & \multicolumn{3}{|c|}{ Male participant } & \multicolumn{3}{|c|}{ Female participant } \\
\hline & $\begin{array}{c}\text { Pre- } \\
\text { exercise }\end{array}$ & Post-exercise & $\begin{array}{c}\text { Recovery } \\
\text { time }\end{array}$ & $\begin{array}{c}\text { Pre- } \\
\text { exercise }\end{array}$ & Post-exercise & $\begin{array}{c}\text { Recovery } \\
\text { time }\end{array}$ \\
\hline glucose $[\mathrm{mmol} / \mathrm{L}]$ & 4.6 & 5.6 & 4.9 & 5.3 & 6.2 & 5.5 \\
\hline creatinine $[\mu \mathrm{mol} / \mathrm{L}]$ & 101 & 91 & 93 & 82 & 91 & 83 \\
\hline urea $[\mathrm{mmol} / \mathrm{L}]$ & 7.5 & 7.1 & 6.6 & 6.2 & 7.5 & 6.5 \\
\hline albumin $[\mathrm{g} / \mathrm{L}]$ & 48.8 & 54.2 & 49.6 & 47.0 & 49.5 & 46.2 \\
\hline total protein $[\mathrm{g} / \mathrm{L}]$ & 69.57 & 78.76 & 70.35 & 71.37 & 76.65 & 69.92 \\
\hline uric acid $[\mu \mathrm{mol} / \mathrm{L}]$ & 272 & 210 & 224 & 233 & 185 & 222 \\
\hline $\begin{array}{l}\text { direct bilirubin } \\
{[\mu \mathrm{mol} / \mathrm{L}]}\end{array}$ & 12.81 & 5.06 & 10.19 & 7.80 & 2.36 & 4.00 \\
\hline $\begin{array}{l}\text { total bilirubin } \\
{[\mu \mathrm{mol} / \mathrm{L}]}\end{array}$ & 19.48 & 9.60 & 17.79 & 12.86 & 6.46 & 4.94 \\
\hline $\mathrm{TG}[\mathrm{mmol} / \mathrm{L}]$ & 0.69 & 0.69 & 0.64 & 0.38 & 0.93 & 0.39 \\
\hline $\mathrm{TC}[\mathrm{mmol} / \mathrm{L}]$ & 3.49 & 3.56 & 3.35 & 4.23 & 4.29 & 4.06 \\
\hline HDL-C [mmol/L] & 1.29 & 1.48 & 1.36 & 2.01 & 2.10 & 1.93 \\
\hline LDL-C $[\mathrm{mmol} / \mathrm{L}]$ & 1.89 & 1.77 & 1.70 & 2.05 & 1.77 & 1.95 \\
\hline amylase [U/L] & 70.9 & 81.1 & 70.7 & 53.1 & 50.2 & 47.1 \\
\hline AST [U/L] & 40.0 & 61.3 & 30.6 & 33.8 & 55.5 & 29.5 \\
\hline ALT [U/L] & 25.8 & 27.6 & 23.8 & 19.5 & 19.7 & 17.7 \\
\hline GGT [U/L] & 9.5 & 9.7 & 9.4 & 6.2 & 6.5 & 5.8 \\
\hline LDH [U/L] & 364 & 395 & 359 & 398 & 428 & 370 \\
\hline $\mathrm{HBDH}[\mathrm{U} / \mathrm{L}]$ & 178 & 196 & 170 & 326 & 220 & 187 \\
\hline $\mathrm{CK}$ [U/L] & 565.2 & 389.8 & 304.5 & 278.2 & 234.0 & 259.2 \\
\hline CK-MB [U/L] & 19 & 16 & 16 & 20 & 13 & 13 \\
\hline ALP [U/L] & 31.05 & 29.73 & 30.18 & 21.07 & 30.80 & 11.46 \\
\hline lipase $[\mathrm{U} / \mathrm{L}]$ & 62.0 & 42.6 & 32.7 & 58.0 & 42.2 & 57.3 \\
\hline
\end{tabular}

TG - triglycerides; TC - total cholesterol; HDL-C - high-density lipoprotein cholesterol; LDL-C - low-density lipoprotein; AST - aspartate aminotransferase (EC 2.6.1.1);

$A L T$ - alanine aminotransferase (EC 2.6.1.2); GGT - gamma-glutamyltransferase (EC 2.3.2.2);

LDH - lactate dehydrogenase (EC 1.1.1.27); HBDH - alfa-hydroxybutyrate dehydrogenase (EC 1.1.1.30); $C K$ - creatine kinase (EC 2.7.3.2); CK-MB - creatine kinase $M B$ (EC 2.7.3.2); ALP - alkaline phosphatase (EC 3.1.3.1) 


\begin{tabular}{|c|c|c|c|c|c|c|}
\hline \multicolumn{7}{|c|}{$\begin{array}{l}\text { Table } 3 \\
\text { The percentages of selected white blood cells' subsets of both participants } \\
\text { determined before (pre-exercise) and after the progressive exercise test } \\
\text { on rowing ergometer until exhaustion (5 minutes post-exercise } \\
\text { and during recovery, } 17 \text { hours after the test) }\end{array}$} \\
\hline & \multicolumn{3}{|c|}{ Male participant } & \multicolumn{3}{|c|}{ Female participant } \\
\hline & $\begin{array}{c}\text { Pre- } \\
\text { exercise }\end{array}$ & $\begin{array}{l}\text { Post- } \\
\text { exercis } \\
\text { e }\end{array}$ & $\begin{array}{l}\text { Recovery } \\
\text { time }\end{array}$ & $\begin{array}{c}\text { Pre- } \\
\text { exercise }\end{array}$ & $\begin{array}{c}\text { Post- } \\
\text { exercise }\end{array}$ & $\begin{array}{c}\text { Recover } \\
\text { y time }\end{array}$ \\
\hline $\begin{array}{l}\text { Lymphocytes } \\
\text { (CD45+SSClow) [\%] }\end{array}$ & 30.80 & 28.87 & 29.70 & 21.10 & 31.17 & 18.91 \\
\hline $\begin{array}{l}\text { T lymphocytes } \\
\left(\mathrm{CD}^{2} 5^{+} \mathrm{CD}^{+}\right)[\%]\end{array}$ & 66.46 & 52.89 & 64.58 & 71.42 & 65.38 & 70.91 \\
\hline $\begin{array}{l}\text { Th lymphocytes } \\
\left(\mathrm{CD}^{+}{ }^{+} \mathrm{CD} 4^{+}\right)[\%]\end{array}$ & 60.97 & 57.69 & 65.07 & 56.01 & 44.95 & 56.00 \\
\hline $\begin{array}{l}\text { Tc lymphocytes } \\
\left(\mathrm{CD}^{+}{ }^{+} \mathrm{CD}^{+}\right)[\%]\end{array}$ & 33.90 & 35.95 & 29.87 & 32.65 & 37.39 & 32.81 \\
\hline $\begin{array}{l}\text { B lymphocytes } \\
\left(\mathrm{CD}^{-}-\mathrm{CD} 19^{+}\right)[\%]\end{array}$ & 16.35 & 16.44 & 16.43 & 7.96 & 6.06 & 6.53 \\
\hline $\begin{array}{l}\text { NK cells } \\
\left(\mathrm{CD} 3-\mathrm{CD} 16^{+}\right. \\
\left.\text {and/or } \mathrm{CD} 56^{+}\right) \\
{[\%]}\end{array}$ & 15.90 & 25.95 & 17.64 & 17.72 & 28.64 & 18.07 \\
\hline
\end{tabular}

White blood cell count after the test increased almost twice as compared to the baseline values in both rowers (from $6.3 \times 10^{9} / \mathrm{L}$ pre-exercise to $12.3 \times 10^{9} / \mathrm{L}$ post-exercise in case of male rower and from $5.2 \times 10^{9} / \mathrm{L}$ pre-exercise to $10.2 \times 10^{9} / \mathrm{L}$ post-exercise in case of female rower). Interestingly, the percentages of natural killer (NK) cells (CD3-CD16 ${ }^{+}$and/or $\mathrm{CD}^{-} 6^{+}$) were higher and total $\mathrm{T}$ lymphocytes $\left(\mathrm{CD} 45^{+} \mathrm{CD} 3^{+}\right)$were lower after the test in comparison with the values found before the test. It was also found that there were higher percentages of suppressor/cytotoxic $\mathrm{T}$ lymphocyte (Tc; $\left.\mathrm{CD}^{+} \mathrm{CD}^{+}\right)$and lower percentages of helper/inducer $\mathrm{T}$ lymphocyte (Th; $\left.\mathrm{CD}^{+} \mathrm{CD}^{+}\right)$subsets in both studied rowers. No changes in $\mathrm{B}\left(\mathrm{CD} 3^{-} \mathrm{CD} 19^{+}\right)$lymphocyte distribution in both participants were observed (Table 3).

No changes in inflammatory cytokines' (IL-8, IL$1 \beta$, IL-6, IL-10, TNF, and IL-12p70) and CRP levels after the maximal effort as well as during recovery in both studied participants were found. Interestingly, the values found for the CRP level in the male and female rowers plasma were equal $0 \mathrm{mg} / \mathrm{L}$ in case of the use two different turbidimetric methods and the values for the cytokines were below the sensitivity of the detection level described by the manufacturer.

\section{Discussion}

Training cycles, in general, force both central and peripheral adaptations, and alter neural recruitment patterns. Physical training causes significant changes in muscle bioenergetics and morphology, substrate metabolism and acidbase status in skeletal muscles (Hawley, 2002). It is well known that rowing races, despite their short duration, could initiate the fatty- and amino acid metabolism (Desgorces et al., 2008).

According to the technical analysis of rowing movements, this type of effort involves both, the shoulder- and pelvic girdle. Analysis of 
the rowing motion indicates that abdominal muscles and those of the pelvic rim are the main driving force of the athlete (Readi et al., 2015). However, in case of adaptive rowing, shoulder girdle muscle are the only propeller.

Our previous research showed that maximum oxygen uptake $\left(\mathrm{VO}_{2 \max }\right)$ observed in case of rowers was within the range of $61-63$ $\mathrm{mL} / \mathrm{min} / \mathrm{kg}$ and $48-53 \mathrm{~mL} / \mathrm{min} / \mathrm{kg}$ for men and women, respectively. It is worth noting that $\mathrm{VO}_{2 \max }$ values found for the studied athletes are similar those of soccer players with 10 year training experience. Moreover, the analysed male participant's $\mathrm{VO}_{2 \max }$ value found in this study was only $4.6 \%$ lower than the lower range of typical values found in the Polish rowing population. Female participant's $\mathrm{VO}_{2 \max }$ registered in our study was only $1.2 \%$ lower than the higher range of typical values of the Polish competitive rowing population. These values indicate a very high fitness level of studied athletes who row using only the shoulder girdle.

Testing rowers in simulated conditions using a rowing ergometer enables to obtain results reflecting those reached in natural (racing shell, on water) conditions (Buckeridge et al., 2015; Fleming et al., 2014). Interestingly, the values of some biochemical variables analysed in this study were above the reference range values established for the general population. The high level of CK activity is typical among athletes, but in our study it was observed that after the maximal effort these values did not rise during recovery. This suggests that the specialized movement did not cause muscle damage in highly qualified rowers. According to the literature, an increase in AST activity is connected with muscle injury caused by physical exercise (Banfi et al., 2012; Fallon, 2008; Lippi et al., 2011). The results of AST activity observed in our study confirm the above-mentioned hypothesis, since the AST activities decreased during recovery in both athletes. Based on the experimental data it should be pointed out that LDH as well as $\mathrm{HBDH}$ activities decreased in

both studied rowers during the recovery period. The most probable explanation of these observations is that there was a relationship between post-exercise changes induced by regular training and the maximum effort implemented during the study. It was also found that specialized movement performed on the rowing ergometer did not cause changes in other studied enzymatic markers belonging to the typical clinical chemistry profile.

Analysing clinical chemistry variables characterising studied participants, a high level of bilirubin before the exercise protocol and during recovery was observed. It is well known that bilirubin production is strictly dependent on erythrocyte haemolysis (which is often highly increased in athletes) and haemoglobin catabolism. Although haemolysis in athletes has been studied during acute exercise, it is difficult to evaluate its influence over an entire competitive season (Banfi et al., 2012). Moreover, it was found that maximal effort caused a decrease in the iron but no changes in the ferritin level. Some observed changes in ions and metabolites concentration (e.g. magnesium, uric acid) immediately after the exercise may be related to the dehydration of athletes. Decreases of about $2 \%$ in haematocrit values and $1 \%$ in total protein and albumin concentrations in blood of both rowers were observed. Interestingly, during the analysis of clinical chemistry characteristics of these athletes performed before the preparatory phase of the training programme (after the Paralympic Games in Rio 2016), those changes were not observed.

It must be emphasised that after maximal effort on the rowing ergometer white blood cell total count was twice as high as baseline values in both participants. The flow cytometric analysis indicated a 1.6-fold higher percentage of NK cells after the exercise in comparison to baseline values among both participants, but no changes in B cells and some minor fluctuation in $\mathrm{T}$ cell subsets distribution. Additionally, there was no cytokine release observed neither after the exercise nor during recovery. Those observations may indicate a high level of biological adaptation to physical exercise of both studied rowers. On the other hand, these results suggest that specialized movement on a rowing ergometer did not cause inflammation even in case of highly exhaustive effort such as the progressive exercise test. It seems that the increase in total WBC count was not related to the immunological response, but only to dehydration of the participants that was also observed by Penkman et al. (2008). 


\section{Conclusions}

Specialized movement performed on the rowing ergometer caused general changes in clinical chemistry variables. It is worth noting that this type of exercise in case of elite paralympic rowers did not cause an increase in CK activity during recovery. Moreover, no inflammatory symptoms were found during the experiment, which suggests a high level of participants' biological adaptation to physical exercise of high intensity.

In conclusion, the different changes in physiological, biochemical and immunological variables are related to the adaptive mechanisms to physical exercise, directed at improving aerobic and anaerobic performance of athletes. Therefore, it is crucial to monitor and adapt the training process individually for each athlete.

\section{Acknowledgments}

The authors would like to thank the rowers and their coach who volunteered to participate in the study.

\section{References}

Akça F. Prediction of rowing ergometer performance from functional anaerobic power, strength and anthropometric components. J Hum Kinet, 2014; 41: 133-142

Banfi G, Colombini A, Lombardi G, Lubkowska A. Metabolic markers in sports medicine. Adv Clin Chem, 2012; 56: $1-54$

Beaver WL, Wassermann K, Whipp BJ. A new method for detecting anaerobic threshold by gas exchange. J Appl Physiol, 1986; 60: 2020-2027

Buckeridge EM, Bull AM, McGregor AH. Biomechanical determinants of elite rowing technique and performance. Scand J Med Sci Sports, 2015; 25: e176-e183

Chamera T, Spieszny M, Klocek T, Kostrzewa-Nowak D, Nowak R, Lachowicz M, Buryta R, Cieszczyk P. Could biochemical liver profile help to assess metabolic response to aerobic effort in athletes? J Strength Cond Res, 2014; 28: 2180-2186

Chamera T, Spieszny M, Klocek T, Kostrzewa-Nowak D, Nowak R, Lachowicz M, Buryta R, Ficek K, Eider J, Moska W, Cieszczyk P. Post-effort changes in activity of traditional diagnostic enzymatic markers in football players' blood. J Med Biochem, 2015; 34: 179-190

Desgorces FD, Testa M, Petibois C. Training-level induced changes in blood parameters response to onwater rowing races. J Sports Sci Med, 2008; 7: 425-430

Fallon KE. The clinical utility of screening of biochemical parameters in elite athletes: analysis of 100 cases. Br J Sports Med, 2008; 42: 334-337

Fleming N, Donne B, Mahony N. A comparison of electromyography and stroke kinematics during ergometer and on-water rowing. J Sports Sci, 2014; 32: 1127-1138

Gee TI, Caplan N, Christian Gibbon K, Howatson G, Grant Thompson K. Investigating the Effects of Typical Rowing Strength Training Practices on Strength and Power Development and 2,000 m Rowing Performance. J Hum Kinet, 2016; 50: 167-177

Hawley JA. Adaptations of skeletal muscle to prolonged, intense endurance training. Clin Exp Pharmacol Physiol, 2002; 29: 218-222

Kyparos A, Riganas C, Nikolaidis MG, Sampanis M, Koskolou MD, Grivas GV, Kouretas D, Vrabas IS. The effect of exercise-induced hypoxemia on blood redox status in well-trained rowers. Eur J Appl Physiol, 2012; 112: 2073-2083 
Lippi G, Schena F, Montagnana M, Salvagno GL, Banfi G, Guidi GC. Significant variation of traditional markers of liver injury after a half-marathon run. Eur J Intern Med, 2011; 22: e36-e38

Penkman MA, Field CJ, Sellar CM, Harber VJ, Bell GJ. Effect of hydration status on high-intensity rowing performance and immune function. Int J Sports Physiol Perform, 2008; 3: 531-546

Readi NG, Rosso V, Rainoldi A, Vieira TM. Do sweep rowers symmetrically activate their low back muscles during indoor rowing? Scand J Med Sci Sports, 2015; 25: e339-e352

Schaffert N, Mattes K. Effects of acoustic feedback training in elite-standard Para-Rowing. J Sports Sci, 2015; 33: $411-418$

Shaharudin S, Agrawal S. Muscle synergies during incremental rowing $\mathrm{VO}_{2 \max }$ test of collegiate rowers and untrained subjects. J Sports Med Phys Fitness, 2016; 56: 980-989

Skarpańska-Stejnborn A, Basta P, Trzeciak J, Szcześniak-Pilaczyńska Ł. Effect of intense physical exercise on hepcidin levels and selected parameters of iron metabolism in rowing athletes. Eur J Appl Physiol, 2015; 115: 345-351

Smoljanovic T, Bojanic I, Hannafin JA, Urhausen A, Theisen D, Seil R, Lacoste A. Complete inclusion of adaptive rowing only $1000 \mathrm{~m}$ ahead. Br J Sports Med, 2013; 47: 819-825

Smoljanovic T, Bojanic I, Pollock CL, Radonic R. Rib stress fracture in a male adaptive rower from the arms and shoulders sport class: case report. Croat Med J, 2011; 52: 644-647

The IDF consensus worldwide definition of the metabolic syndrome [Electronic version] Available at: http://www.idf.org/metabolic-syndrome; accessed on 24.07.2014

Tran J, Rice AJ, Main LC, Gastin PB. Convergent validity of a novel method for quantifying rowing training loads. J Sports Sci, 2015; 33: 268-276

WHO. Cardiovascular diseases. Available at: http://www.who.int/topics/cardiovascular_diseases/en/; accessed on 24.07.2014

\section{Corresponding author:}

\section{Dorota Kostrzewa-Nowak,}

Centre for Human Structural and Functional Research,

Faculty of Physical Education and Health Promotion,

17C Narutowicza St.

70-240 Szczecin, Poland,

Phone: +48914441077

E-mail: dorota.kostrzewa-nowak@usz.edu.pl 